\title{
Los Incoterms a través de la Autonomía Conflictual Incoterms through Conflictual Autonomy
}

Recibido: 23/05/19

\author{
Eduardo Andrés Calderón Marenco \\ Universidad Centroamericana, Nicaragua. \\ eduardo.calderon.marenco@gmail.com
}

Aceptado: 29/06/19

\begin{abstract}
Resumen: En las últimas décadas, en el seno de la sociedad de comerciantes se ha instaurado un nuevo ordenamiento jurídico, permitiendo el resurgimiento de la Lex Mercatoria como fuente de este Derecho. Ello ha generado un amplio debate en torno a la aparición de la nueva Lex Mercatoria en el Derecho mercantil internacional, discutiéndose, entre muchos aspectos, su papel en el sistema de fuentes jurídicas y, en consecuencia, su aptitud para ser fuente de Derecho en la resolución de los conflictos mercantiles tanto en el ámbito jurisdiccional Estatal como en el plano arbitral. Antes de esto, es necesario exponer las razones de la vigencia de la autonomía conflictual en este sector, y analizar las condiciones y las consecuencias de una elección del derecho aplicable en el Derecho de los contratos internacionales, así como sus límites, los que llevará a determinar la aplicación de la Lex Mercatoria en virtud de la autonomía conflictual de las partes y, más específicamente, la elección de los Incoterms como manifestación de este nuevo ordenamiento jurídico.
\end{abstract}

Palabras claves: Lex Mercatoria; Incoterms; Autonomía Conflictual; Estados; Comercio Internacional 
Eduardo Andrés Calderón Marenco

Abstract: In the last decades, within the merchants' society a new legal system has been established, allowing the resurgence of the Lex Mercatoria as a source of this Law. This has generated a wide debate around the appearance of the new Lex Mercatoria in international commercial law, discussing, among many aspects, its role in the system of legal sources and, consequently, its aptitude to be a source of law in the resolution of commercial conflicts both in the State jurisdictional scope and in the arbitral level. Before this we must explain the reasons for the validity of conflictual autonomy in this sector, and analyze the conditions and consequences of a choice of law applicable in the law of international contracts, as well as their limits, which will lead us to determine the application of Lex Mercatoria by virtue of the conflictual autonomy of the parties and, more specifically, the choice of Incoterms as a manifestation of this new legal system.

Keywords: Lex Mercatoria; Incoterms; Conflict Autonomy; State; International Trade

Sumario: Introducción. I. Autonomía Conflictual. El derecho de elección de las partes contractuales. 1. Aspectos Fundamentales. 2. Ventajas y diferencia entre Autonomía Conflictual y Norma de Conflicto. 3. Derechos elegibles a partir de la Autonomía Conflictual. Lex Mercatoria, un nuevo ordenamiento jurídico II. Incoterms. Usos y costumbres internacionales. 1. Contexto histórico y clasificación. 2. Naturaleza y alcance de los contenidos. 3. Los Incoterms y la Convención de Viena de 1980 sobre compraventa internacional de mercaderías. Fundamento Legal. III. Aplicación de los Incoterms como Lex Mercatoria (usos y costumbres) a partir de la Autonomía conflictual. IV. Aportes y Resultados. Bibliografía.

\section{Introducción}

En el marco del proceso de Globalización, las significativas transformaciones que operan en el campo político, social y especialmente económico, representan importantes desafíos en la esfera jurídica. La creciente actividad comercial en el 
Los Inconterms a través de la Autonomía Conflictual

plano internacional, provocó cambios para el desarrollo de un nuevo Derecho que permitiera la regulación efectiva de actividad comercial. La costumbre como fuente de Derecho tomó vida mediante la autonomía de la voluntad de los contratantes con el ánimo de brindar una solución a la problemática que planteaba las legislaciones nacionales como Derecho aplicable, las cuales no resolvían las particularidades del tráfico comercial. Por ende, las partes y su vinculación con la autonomía conflictual -libertad para elegir el Derecho aplicable-configuraron un nuevo ordenamiento denominado Lex Mercatoria.

Este nuevo ordenamiento jurídico, sin necesidad de ser Derecho positivo o estatal, recoge los usos y costumbre más relevantes en el comercio internacional; una manifestación de la Lex Mercatoria son los Incoterms. Por tanto, se pretende explicar en esta investigación que estos términos comerciales pueden fungir como Derecho aplicable en los contratos internacionales de compraventa de mercaderías con el solo hecho que las partes mediante la autonomía conflictual así lo decidan; es decir que se demostrará que estos términos son un instrumento jurídico efectivo para regular los aspectos fundamentales relativos a la transmisión de mercaderías.

Para poder afirmar lo anterior, en línea de principio, debe realizarse un estudio de la autonomía conflictual como potestad de las partes a elegir un Derecho aplicable al contrato. Posteriormente, es preciso traer a colación las posiciones doctrinarias más aceptadas sobre el reconocimiento de la Lex Mercatoria en el ordenamiento jurídico, al igual que sus mayores límites; y, por último, se pretende realizar un estudio pormenorizado de los Incoterms de cara a su inclusión como Derecho del contrato; por tanto esta investigación es de corte teórica y analítica siendo que expondrá y analizará las posturas más relevantes y aceptadas de la doctrina entorno a la tesis propuesta.

\section{Autonomía Conflictual. EI derecho de elección de las partes contractuales}


Eduardo Andrés Calderón Marenco

\section{Aspectos Fundamentales}

En este punto de partida debe reflexionarse que hasta el día de hoy la costumbre en el Derecho Mercantil sigue siendo una maquinaria generadora de Derechos a partir de los usos y costumbres (Lex Mercatoria), que en muchas ocasiones no están positivados por las legislaciones nacionales; sin embargo, actualmente han tenido fundamento en las contrataciones internacionales mediante la aplicación de la autonomía de la voluntad de las partes contratantes, principio del Derecho recogido por la mayoría de ordenamientos jurídicos nacionales de distintos sistemas legales.

Motivada por los cambios tecnológicos, comerciales e industriales y por la misma Globalización que se ha producido en una gran parte de las economías del mundo, la autonomía conflictual ha venido a revolucionar los negocios jurídicos de compraventa internacional de mercaderías, dado que, habida cuenta el Derecho Internacional Privado y su sistema conflictual, hoy en día, se revela insuficiente para cubrir el amplio elenco de cuestiones que producen los contratos mercantiles, y los sistemas nacionales se alejan en gran medida para otorgar soluciones acordes a las prácticas comerciales dado que muchos de los Códigos de Comercio o Mercantiles, parten de una realidad pre industrial anclada en los tipos contractuales tradicionales que no previeron los cambios tecnológicos, industriales y comerciales hoy imperantes (Gómez Segade y García Vidal, 2010).

Para Leible (2011) la autonomía privada debe entenderse como la libertad de las partes de configurar sus relaciones libremente y bajo su responsabilidad, o lo que bien llaman autonomía material, que concede a las partes el Derecho a decidir por sí mismas si debe concluirse un contrato y con quién debe concluirse (libertad de contratación), y que contenido debe presentar el contrato (libertad de configuración), en cambio la autonomía conflictual concede a las partes de un contrato, la libertad de elección del Derecho al que se somete la relación jurídica manifestada en la contratación internacional.

Oviedo Albán (2012) agrega que en el Derecho Internacional Privado moderno se admite como regla general para la determinación de la ley aplicable a los contratos internacionales la autonomía de la voluntad, en un doble alcance: 
Los Inconterms a través de la Autonomía Conflictual

material y conflictual, este último término debe entenderse al derecho que las partes pueden escoger la ley o el Derecho que regirá el contrato, bien cabe resaltar a como lo manifiesta el doctrinario la elección de una ley o un Derecho, en cambio Ortiz Vidal expresa que:

La autonomía de la voluntad conflictual es el derecho subjetivo del que disponen los particulares implicados en la celebración de un contrato internacional, que consiste en la facultad de elegir la Ley reguladora del contrato del que forman parte (Ortiz Vidal, 2012, p. 89).

La reflexión realizada por esta autora, puntualiza únicamente que las partes tienen derecho de elegir la "Ley" aplicable y no así como lo dispone Stefan Leible y Jorge Oviedo Alban, siendo que no solamente puede erigirse una ley sino también un Derecho, pero que además, puede elegirse el Juez que resolverá la causa, lo que proporciona una mayor libertad a las partes (Espinoza Quintero, 2009).

Ahora bien, el concepto de autonomía conflictual, como lo han reconocido los autores ya citados, es un concepto moderno que en muchas ocasiones tiende a confundirse con el concepto tradicionalistas de Norma de Conflicto utilizado por el Derecho Internacional Privado, sobre este derrotero se evidencia la necesidad de pautar la diferencia entre ambos.

\section{Ventajas y diferencia entre Autonomía Conflictual y Norma de Conflicto}

El concepto doctrinal de norma de conflicto, es ampliamente reconocido por el Derecho Internacional Privado, según Nuria González Martín y Sonia Rodríguez Jiménez este tipo de normas (Conflictuales):

Determinan que ordenamiento jurídico, que sistema jurídico, de los que se encuentran razonablemente vinculados con el supuesto de hecho dará respuesta al fondo de la cuestión planteada por las partes, a través de sus normas materiales o sustantivas (González Martín \& Rodríguez Jiménez, 2010, p. 138). 
Eduardo Andrés Calderón Marenco

De tal suerte, puede determinarse que, más que un tipo de normativa, estas (nomas de conflicto) son un mecanismo que determinará en el momento de un conflicto entre las partes, el Derecho que se aplicará por parte del tribunal competente para dirimirlo, en otras palabras:

La norma de conflicto señala que ordenamiento jurídico estatal de los diferentes y diversos que están convenientemente relacionados con el supuesto de hecho, deben dar una respuesta al fondo, una solución material concreta, a la pretensión planteada (Dávalos Fernández, 2003, p. 4).

La norma de conflicto no aporta una respuesta directa-sustantiva- al particular problema planteado; no señala cual es la especifica solución material del mismo (Espugles Mota, 2009). Lejos de ello, la norma de conflicto genera una respuesta indirecta que, además, se caracteriza por su carácter apriorístico y abstracto, y por su naturaleza bilateral, y se limita a localizar la situación en un concreto ordenamiento jurídico, ya sea el ordenamiento del foro o un ordenamiento extranjero, en palabras de Arellano García (2006), las normas del Derecho Internacional Privado se concretan a señalar la norma jurídica competente o aplicable para regir una situación concreta mientras que la conducta a seguir por los sujetos destinatarios de la norma se prescribe en la norma sustantiva (norma estatal o nacional).

La ventaja que presenta en la actualidad la autonomía conflictual en relación a la norma de conflicto se fundamenta en la falta de adecuación a las necesidades del comercio internacional, por lo tanto, la práctica internacional ha confirmado en muchas ocasiones los inconvenientes derivados de la hegemonía de las leyes estatales en la regulación de contratos internacionales (Fernández Rozas, 2004). Este método clásico, incoado por el maestro Savigny ha resultado complicado debido a que sus resultados a menudo son inciertos, pues los tribunales nacionales manifiestan una tendencia a favor de la aplicación de la lex fori; sin embargo el objetivo del comercio internacional se aleja de esta postura, máxime que, como se mencionó con anterioridad, gran parte de las normas nacionales nunca fueron concebidas para aplicarse a situaciones internacionales y precisamente el intento de resolver esa insatisfactoria situación motivó el desarrollo del Derecho uniforme que ha tenido como fuente primara la costumbre. 
Es así que, la problemática que presenta la norma de conflicto da lugar al nacimiento o búsqueda de otros mecanismos de regulación considerados más ajustados a las exigencias de la misma Globalización y el comercio, tales como, la unificación del Derecho de los contratos a través de convenios internacionales o de actos de instituciones internacionales a las que los Estados hayan transferido competencias en la materia y la creación por parte de los propios operadores jurídicos y económicos que participan en el comercio internacional de una normativa uniforme o bien de la jurisprudencia generada por órganos arbitrales (Bouza Vidal, 2005), no obstante, esto solo puede consagrarse mediante el principio de libertad de elección del Derecho aplicable a los contratos (autonomía conflictual).

La mayoría de los teóricos, inmersos en la dogmática de la mentalidad moderna, postulan el principio de la autonomía de la voluntad en su vertiente conflictual, en el sentido de afirmar que la ley o Derecho que rige la relación contractual puede ser elegida libremente por las partes, en tanto permite un libre actuar en las contrataciones internacionales realizadas (García Castillo, 2010), siendo este el argumento de más peso que debe prevalecer sin lugar a dudas; además Giménez Corte (2002) agrega que a favor de la libertad de elección se erige la ganancia que presenta en materia de seguridad jurídica, al mismo tiempo, mediante la elección del Derecho las partes obtienen un conocimiento seguro acerca del Derecho vigente, es decir, el Derecho aplicable. Ahora bien, reconocida la importancia de la autonomía conflictual, de la cual la doctrina y la práctica han consagrado como un detonante de certeza jurídica en las transacciones comerciales, debe enmarcarse que tipos de derechos son elegibles a partir de este precepto, lo que se desarrollará a continuación.

\section{Derechos elegibles a partir de la Autonomía Conflictual. Lex Mercatoria, un nuevo ordenamiento jurídico}

La intención de este trabajo de investigación no es delimitar un concepto de Derecho, más aún que doctrinariamente existen un sin número de reflexiones 
Eduardo Andrés Calderón Marenco

que han buscado acercarse a esta definición, cada quien desde su perspectiva ius naturalista, positivista, subjetivista, etc.; sin embargo para efectos de estas líneas investigativas el aporte dado po Ruiz Rodríguez (2009) es el más acorde:

Derecho es visto como norma, empero el jus, que era la palabra técnica latina que usaron los juristas romanos, no tenía, en un principio, ese sentido normativista, y es que ellos (los romanos) utilizaban el jus para designar el Derecho elaborado por los hombres, ese significado primigenio es el que prevalece en la concepción subjetivista del Derecho, lo que hoy se traduce en que Derecho no es sinónimo de ley (p. 38).

El Derecho aplicable a una contratación internacional torna su mirada a las fuentes primarias y secundarias, entre ellas la ley y la costumbre, es por estas razones que debe destacarse la posición de rasgos subjetivistas, la cual defiende que la designación del Derecho aplicable solo depende de lo que quieran las partes (Requejo Isidro, 2013). Siguiendo el esquema del autor uruguayo Quintín Alfonsín citado por Revoredo de Mur (1994), en teoría, el régimen internacional de los contratos internacionales puede quedar establecido de varios modos, el primero de ellos a través de una norma de conflicto que señale el Derecho sustantivo nacional aplicable al contrato, en cambio el segundo método consiste en solucionar el problema contractual internacional por medio de un régimen jurídico sustantivo y dejar al criterio de las partes las normas de Derecho aplicables al contrato, sean normas de un Derecho sustantivo nacional o internacional, o bien, de una ley uniforme o de todos aquellos instrumentos internacionales que hayan sido incorporados al Derecho nacional (convenciones, tratados, etc.), vale decir que pueden crear un nuevo Derecho diseñado exclusivamente para su relación contractual nacido de la costumbre o lo que bien se denomina Lex Mercatoria (usos y costumbres).

Probablemente, no existan problemas cuando se trate de elegir a la ley nacional o un tratado o convención de Derecho internacional ratificado por los Estados, como Derecho aplicable a la contratación partiendo del principio de libre elección o hacer frente a la problemática de no decidir el Derecho y 
dejarlo al arbitrio de la norma de conflicto para determinar la legislación que regirá el contrato, no obstante, el mayor debate práctico y doctrinario está en la invocación de la Lex Mercatoria (usos y costumbres) como Derecho aplicable a la contratación internacional. Por lo que es preciso hacer un esfuerzo de diseñar un concepto de Lex Mercatoria, pero antes de esto, debe plasmarse la pregunta rectora de la problemática que gira entorno a la investigación: ¿Constituye la Lex Mercatoria un auténtico sistema jurídico para ser incorporado por las partes mediante la autonomía conflictual?

Como bien apuntan Fernández Rozas, Arenas García y, Miguel Asensio (2013) cualquier intento de delimitación de Lex Mercatoria, no es tarea fácil, aun tomando en cuenta que no es un concepto moderno; a pesar de esto, se afirma con razón, que no es posible proveer una lista exhaustiva de todos los elementos de la Lex Mercatoria y con respecto a la conceptualización de la así llamada nueva Lex Mercatoria, que ha enfrentado posturas irreconciliables entre mercatoristas $\mathrm{y}$ antimercatoristas, puede comenzarse enunciando un primer concepto ofrecido por Berman y Dasser citados por Cristián Giménez Corte: “Lex Mercatoria es derecho de raíz consuetudinaria, como lo era la vieja Lex Mercatoria de los comerciantes de la edad media" (Giménez Corte' 2002).

Tobar Torres (2012) plasma la noción dada por Goldman, uno de los primeros autores que utilizaron este término, para quien la nueva Lex Mercatoria son: "reglas transnacionales que los participantes en los intercambios económicos internacionales se dan progresivamente a sí mismos, notablemente en el marco de sus organismos profesionales y que los árbitros constatarán y precisarán, teniendo en cuenta la intención de su elaboración".

De ambos conceptos puede delimitarse que La Lex Mercatoria se conforma como un Derecho espontáneo, un nuevo ordenamiento autónomo creado desde un inicio por los comerciantes con el objetivo fundamental de evadir, en sus transacciones, las normas de carácter nacional de sus respectivos países liberándose de la rigidez y de la falta de sensibilidad para el tráfico internacional de estas últimas. Por tanto, básicamente son dos las notas que permiten caracterizarla, su "anacionalidad", es decir, no emana de una sistema jurídico propio de un Estado soberano; y, en segundo término, la fuerza obligatoria que le reconoce la comunidad comercial, esta última connotación se deriva de la participación 
Eduardo Andrés Calderón Marenco

en la elaboración de la nueva Lex Mercatoria por parte de los comerciantes pertenecientes a distintos Estados, con diferentes sistemas políticos, económicos y sociales, así como con distintos niveles de desarrollo (Navarro Pentón, 2009).

Es entonces que, surge el escenario en el que nace un Derecho comercial global independiente de cualquier legislador nacional pero dependiente de instituciones legales y judiciales existentes desde hace tiempo, por cuanto las decisiones arbitrales pueden ser exigidas y perseguidas en tribunales nacionales, ejemplo de esto es la Convención sobre el Reconocimiento y la Ejecución de las Sentencias Arbitrales Extranjeras, conocida como la Convención de Nueva York de 1958 (Fernández Rozas, et al., 2013). No debe extrañar, pues, que la Lex Mercatoria se erija como un orden jurídico propio, aunque sea incompleto y en alguna medida esté subordinado a los órdenes jurídicos nacionales en su aplicación y eficacia, dependencia que no afecta a su autonomía pero si la limita.

Aun previniendo que el Derecho estatal pueda limitar el desarrollo y aplicación de la Lex Mercatoria habrá que tomar en cuenta la expansión de ésta junto con el incremento de la normatividad internacional en el Siglo XXI; en tal sentido, los operadores del comercio se alejan cada vez más de los Derechos nacionales y solo recurren a ellos cuando tengan que hacer ejecutivo un Derecho mediante los órganos coactivos del Estado (Pereznieto Castro, Leonel y Silva Silva' ${ }^{1995)}$. Ahora bien, el contenido de la Lex Mercatoria así como su concepto, se escurre entre diversos doctrinarios, una primera aproximación la brinda Pereznieto Castro (1999), y es que para él la doctrina ha querido describir una amplia serie de reglas emitidas por organismos privados o por órganos intergubernamentales, ambos a nivel internacional, pero cuya característica principal es que se trata de reglas que configuran la Lex Mercatoria aplicables a las contrataciones comerciales internacionales, no obstante, esta no solo se manifiestan en instrumentos de organismos internacionales.

Los aportes de Giménez Corte (2002) se suman a estas líneas; primeramente se determinan a los usos como contenido de esta Lex Mercatoria, constituyen un Derecho espontáneo, uniforme, y en cierta manera universal; que son usos propios de los comerciantes, de ellos encontramos a los contratos internacionales; las condiciones generales de contratación y los standards forms; las reglas de las asociaciones profesionales y las guidelines; los principios generales del 
Los Inconterms a través de la Autonomía Conflictual

comercio internacional, y los restatements of law; los códigos de conducta, las convenciones internacionales aún no vigentes y ratificadas por los Estados y las leyes modelos; y los laudos arbitrales, la normativa procedimental y la equidad.

Esta delimitación de contenido por parte de Cristián Giménez Corte es más específica y concreta, por ello se quiere enfatizar en tres acápites; en primer lugar habrá que otorgarle valor a los contratos comerciales; siendo que constituyen fuente principalísima del Derecho del comercio internacional donde se manifiesta la autonomía conflictual; ante la repetición de los mismos, algunos contratos se han tipificado en condiciones generales, y otros han devenido en usos y costumbres; en segundo término están los usos -aunque no todos- han sido recopilados y sistematizados, como ejemplo se pueden citar a la reglas y usos uniformes para los créditos documentarios y los Incoterms; además muchos usos se han positivizados en normas nacionales e internacionales; y por último se encuentran también los laudos arbitrales, la normativa procedimental y la equidad, hay que tener presente que, a través de los laudos, va a ser posible identificar los principios, reglas y usos que componen la Lex Mercatoria, ya que los árbitros suelen acudir con frecuencia a los mismos (laudos) para dirimir las controversias que ante ellos se suscitan.

Una vez determinado el contenido doctrinario que lo denomina como nueva Lex Mercatoria, debe continuarse a contestar las siguiente interrogante: ¿Están facultadas las partes, por medio de la autonomía conflictual, a elegir como Derecho rector de su contrato a la Lex Mercatoria?, después de lo estudiado es posible determinar afirmativamente que gran parte de la doctrina se inclina por un rotundo SÍ, pero corresponde realizar algunas reflexiones sobre esta interrogante, y es que, en un primer momento, como se dejó sentado, las partes de un contrato pueden elegir como aplicable no solo a un Derecho nacional de un país determinado, sino un Derecho transnacional, considerando que la acepción de Derecho va más allá de una norma positivizada, un Derecho de creación no estatal. La sistematización, el reconocimiento y la valoración de la nueva Lex Mercatoria en el contexto actual del comercio internacional, y las relaciones económicas internacionales que se desarrollan, sustentan la existencia de un cuerpo normativo en que reúne usos de comercio respetados universalmente 
Eduardo Andrés Calderón Marenco

y que, como tal, dan cabida a la creación de normas jurídicas de imperativo cumplimiento (Rodríguez Fernández' 2012).

No es posible crear una postura concreta sin contrastar las críticas y limitantes que tiene este ordenamiento jurídico; la primera objeción que han manifestado los autores detractores de este nuevo concepto, se basa en la clásica teoría de que todo contrato que no ha sido celebrado entre Estados en su calidad de sujetos de Derecho Internacional, deberá someterse a las leyes de un Estado (leyes nacionales), asimismo expresan que este sistema obedece a los intereses y necesidades específicas de un grupo social restando legitimidad dentro del Derecho Internacional puesto que sus promotores son un colectivo poderoso, una nueva societas mercatorum que busca crear una normatividad y un aparato jurisdiccional a su servicio; de manera abundante se estableció la particularidad de la creación por parte de los comerciante de un nuevo Derecho basado en los usos y costumbres, siendo que hoy por hoy la legislaciones nacionales no satisfacen las necesidades del contexto práctico-jurídico del comercio.

Por otra parte, se señala igualmente que la Lex Mercatoria no es autónoma al condicionar su desarrollo a la aceptación que de ella tengan los Derechos estatales; que sobre esta crítica puede apostarse que el Estado y sus normas sustantivas y procesales son en muchas ocasiones limitantes pero que no le resta por completo autonomía; sin embargo la discrepancia de la Lex Mercatoria surge frente a normas imperativas o de orden público, y como bien es sabido las normas de orden público no pueden ser inaplicadas, un ejemplo de ellas son las normas que protegen la competencia y el derecho del consumidor, entre otras.

Zapata De Arbeláez citado por Alzate Ossa (2013) exterioriza la negación de la existencia de una Lex Mercatoria como sistema jurídico en términos positivistas:

En tanto carece de una organización o distribución jerarquizada de normas que incluya normas superiores como la Constitución y normas inferiores como las leyes y los decretos en el sentido expresado por Kelsen; y los principios de la Lex Mercatoria no se encuentran organizados de tal manera por lo tanto, no podrán considerarse como partes de un derecho comercial internacional stricto sensu. 
Esas críticas provienen, en buena medida, de quienes aún consideran la vieja concepción de que sólo el Estado está facultado para producir normas, y que posee una serie de propiedades definitorias como la sistematización e institucionalización de normas, la seguridad y la previsibilidad de comportamientos y decisiones, la existencia de un cuerpo burocrático que se encarga de su administración y, finalmente, la garantía coactiva de su cumplimiento.

Para culminar este primer apartado debe responderse a las preguntas acotadas, y es que una vez revisada la doctrina válida es permitido enmarcar a la Lex Mercatoria como un nuevo ordenamiento jurídico, es decir, el resurgimiento del Derecho consuetudinario creado por comerciantes, que si bien es cierto no es completamente autónomo e independiente porque aún presenta algunas aristas relacionadas con el Derecho estatal, concretamente en los límites establecidos por el orden público y reconocimientos en la ejecución de laudos, por lo tanto tomando en consideración al Derecho que le asiste a las partes otorgado por la autonomía conflictual, pueden elegir a la Lex Mercatoria como Derecho aplicable al contrato, así lo ha reconocido la doctrina mayoritaria y los órganos jurisdiccionales arbitrales, pero bien, continuando con el orden de ideas de esta investigación, como se estableció en precedencia, una de las manifestaciones de la Lex Mercatoria han sido los Incoterms, por lo que es importante dejar establecida desde ya esta premisa.

\section{Incoterms. Usos y costumbres internacionales}

\section{Contexto histórico y clasificación}

$\mathrm{Su}$ origen se enclava en el desarrollo del comercio mundial, permitiendo dar pautas a los acuerdos entre las partes contratantes, vaciando en gran medida a los contratos de compraventa internacional de su personalidad nacional. La primera etapa histórica se originó en el primer congreso de la Cámara de Comercio 
Eduardo Andrés Calderón Marenco

Internacional (CCI), realizado en Paris en 1920, donde se iniciaron los trabajos que resultarían en el estudio del Derecho, usos y prácticas de más de 30 países, conclusiones que se editaron en 1928, pero la versión completa se pregonó en 1936 la cual recibió el nombre de Incoterms (International Comercial Terms) por sus siglas en inglés (Fratalocchi, 1994).

Tal como comparten Chuliá Vicent y Beltrán Alandete (1995), desde principios del pasado siglo, el comercio internacional experimenta gran auge pero al empresario comerciante, que a título individual o agrupado en sociedades mercantiles comercia con otras naciones, se le presentaban graves problemas como consecuencia del desconocimiento de las leyes de otros Estados; el de sus usos y costumbre; el idioma, etc. Lo que motivo la creación de estos términos (Incoterms) que permitiesen, con el mínimo esfuerzo, conocer los derechos y obligaciones de las partes en la compraventa internacional de mercaderías. Después de su primera publicación obtuvieron un gran éxito (lo cual era de esperarse por reunir los usos y costumbre de más de 30 países); no obstante, el uso y la experiencia aconsejaron ampliaciones en 1953, 1967, 1976, 1980, 1990, 2000 y 2010, para la versión original incluyeron 11 términos (Sosa, 2012).

Las siglas que representan un Incoterms determinado han sufrido variaciones debido al cambio en los usos y costumbres en el negocio jurídico de compraventa internacional de mercaderías, prácticamente cada revisión y publicación es influenciada por las críticas positivas de igualar con una interpretación idéntica los términos comerciales más empleados en las operaciones de compraventa internacionales (Huamán Sialer, 2013).

La Cámara de Comercio Internacional (2010) en la última revisión de los Incoterms en el año 2010 enfoca la gran influencia que la economía global ha proporcionado a las empresas, generándoles un mayor acceso a los mercados de todo el mundo, como consecuencias de las ventas de mercancías en más países, en más cantidad y con más variedad, a lo que puede apuntarse como una característica del denominado fenómeno de Globalización; además es consciente de la naturaleza de estos términos, por ende deja claro que la interpretación de la regla Incoterms que se elija puede estar muy influenciada por las costumbres concretas del puerto o lugar utilizado; no obstante esta aseveración permite

\section{DERECHO GLOBAL. ESTUDIOS SOBRE DERECHO Y JUSTICIA}


reforzar la tesis, que aunque no es objeto de estudio de esta investigación, sobre la limitante que en muchas ocasiones generan las legislaciones nacionales.

Por último, incorporó aspectos relevantes, el primero de ellos siguiendo el ejemplo de la Unión Europea que ha provocado que los tráficos fronterizos entre varios países sean menos significativos, por tanto se ha permitido que estos usos puedan utilizarse en contratos de compraventa nacional. El segundo aspecto, versa sobre las comunicación electrónica siendo que las reglas Incoterms 2010 otorgan ahora a los medios de comunicación electrónicos el mismo efecto que la comunicación en papel, en la medida en que las partes así lo acuerdan o cuando se da la costumbre, esta fórmula facilita la evolución de nuevos procedimientos electrónicos durante la vigencia de las reglas Incoterms 2010, ahora bien, puede conocerse un poco más sobre la clasificación actual.

Los términos que contiene la versión actual son: EXW (Entrega en Fábrica en lugar convenido), FCA (Franco transportista lugar convenido), FAS (Franco al costado del buque puerto de carga convenido), FOB (Franco a bordo en puerto de carga convenido), CFR (Coste y flete hasta puerto de destino convenido) CPT (Transporte pagado hasta puerto de destino convenido), CIF (Coste, seguro y flete), CIP (Transporte y seguro pagados hasta, puerto de destino convenido), DAT (Entregado en terminal de puerto de destino convenido), DAP (Entregado en un punto, lugar de destino convenido) y DDP (Entregado derechos pagados hasta lugar de destino convenido); estos se encuentran agrupados en cuatro grupos.

El grupo E implica el mínimo de obligaciones para el vendedor, pues éste cumplirá su obligación de entrega poniendo a disposición del comprador la mercancía en su propio almacén o fábrica; el grupo $\mathrm{F}$ tiene como característica común el hecho de que dejan a cargo del comprador los gastos principales del transporte de la mercadería; mientras el vendedor se obliga a entregar la mercancía al transportista, designado por el adquirente, en un lugar y tiempo determinado y hasta ese momento asume los gastos de transporte y los riesgos derivados de la posible pérdida o daño de los bienes negociados; el grupo C se caracteriza porque la entrega se produce, como norma general, en el medio de transporte designado por el vendedor, quien corre con los gastos de transporte, pero no asume los riesgos de pérdida o daño de la mercancía desde el momento en que se produce la entrega, por último, en el grupo D el exportador asume todos los 
Eduardo Andrés Calderón Marenco

gastos y riesgos necesarios para llevar las mercancías a un lugar específico dentro del país de destino y el importador tiene menos obligaciones y recibe los bienes en su propia bodega.

En estos momentos, los Incoterms son objeto de estudio y revisión por parte de la CCI, sus subcomisiones y grupos de trabajo en todo el mundo, y se espera la publicación de una nueva versión en el año 2020 (León Robayo, 2019).

Está previsto que incorpore el término CNI (Coste y Seguro), en virtud del cual el vendedor (exportador) será quien asuma el coste del seguro internacional, sin hacerse cargo del flete. Además, el riesgo de transporte se transmitiría del vendedor al comprador en el puerto de salida. Por otra parte, también se está planteando la aparición de dos nuevos términos como fruto de la desagregación de un Incoterms muy utilizado en el comercio internacional: el FCA (Franco Transportista). Uno para entregas terrestres y otro para entregas marítimas, sin sufrir modificaciones en cuanto a la designación de responsabilidades entre las partes. De forma análoga, se prevé desdoblar el término DDP (Entrega Derechos Pagados) en dos Incoterms, en función de si la entrega se produce en una terminal (Puerto, Aeropuerto,) en el país del comprador (DTP, Entregada; Terminal Pagada) o si la entrega se produce en cualquier otro lugar, distinto de una terminal de transportes (p. ej. el domicilio social del comprador). En este último caso pasaría a denominarse DPP (Entregada; Lugar Pagado). En ambos términos se mantendría la condición de que es el vendedor el que asume el pago de los derechos aduaneros (AFI, 2019).

\section{Naturaleza y alcance de los contenidos}

Sobre este tema, diversos autores han dejado sentada su posición, entre ellos, Aldo Fratalocchi (1994), conceptualizándolos como: "un conjunto de reglas internacionales, de aceptación voluntaria por las partes, que determina el alcance de las cláusulas comerciales incluidas en el contrato de compraventa", además regulan especialmente las condiciones de entrega, distribución de gastos, transferencia de riesgos, documentos, etc. Conjuntamente es sabido que no existen

\section{2}


Los Inconterms a través de la Autonomía Conflictual

cláusulas Incoterms sin contrato de compraventa internacional, sumando a esto su importancia radica en reducir las incertidumbres derivadas de las múltiples interpretaciones que países con legislación, usos y costumbres diferentes. A esta posición se suma Jerez Riesco (2007), y es que desde el punto de vista de la naturaleza jurídica de los Incoterms, estos tienen carácter facultativo, no es obligatoria su utilización a menos que las partes así lo invoquen en su contrato de compraventa internacional de mercaderías.

Con fundamento en las consideraciones anteriores, debe puntualizarse que los Incoterms también son considerados como instrumentos de Derecho Suave (Soft Law), para Pereznieto Castro (2013) este término (Derecho Suave o Derecho Flexible) es aquel emitido por los organismos internacionales que por su flexibilidad se acomodan a diversas situaciones y reducen la contradicción entre sistemas, además este tipo reglas ayudan para que las partes en sus contratos puedan adecuarlas e incorporarlas y hacerlas obligatorias, ya que en el comercio internacional, este tipos de instrumentos se nutren de la Lex Mercatoria, otra característica fundamental de este Derecho es que no poseen efectos vinculantes, a menos que las partes los incluyan en sus contratos a través de la autonomía conflictual.

Sobre el alcance de los mismos, se mencionó que describen principalmente las obligaciones, costes y riesgos que implica la entrega de las mercancías de los vendedores a los compradores, definitivamente son muy importantes pero no regulan todos los aspectos del cumplimiento del contrato de compraventa de mercaderías, en si regulan: 1) Lugar y condiciones de entrega de las mercancías, 2) Transmisión de los riesgos del vendedor al comprador en el momento de la entrega, y 3) Reparto de costes, como los de seguro, flete o las licencias de importación y entrega de documentos (Ruiz Castellanos' 2012). 
Eduardo Andrés Calderón Marenco

\section{Los Incoterms y la Convención de Viena de 1980 sobre compraventa internacional de mercaderías. Fundamento Legal}

No puede existir Incoterms sin el negocio jurídico de compraventa internacional de mercaderías, fueron creados con el propósito de complementar estas transacciones comerciales, tal como fue establecido en líneas anteriores. En 1980 entra en vigencia la Convención de Viena sobre compraventa internacional de mercaderías, derivada de un arduo trabajo que partió desde 1909, en su elaboración estuvieron involucrados asociaciones de comerciantes, Estados y organizaciones como CNUDMI (Comisión de las Naciones Unidas para el Derecho Mercantil Internacional); la creación de esta norma tuvo un importante aporte para la configuración de un nuevo Derecho Internacional en el plano mercantil, con el ánimo de que facilitara los intercambios de bienes, capitales y servicios en un monto que tiende a la Globalización económica denotando la creación de un derecho supra nacional (Calderón Marenco, 2017).

La convención ratificada por los Estados pasa a ser Derecho nacional y es importante su mención siendo que en ella se reconoce el Derecho de las partes de invocar y regular sus transacciones por los usos y costumbres mercantiles, esta premisa va encaminada a establecer el sustento legal que pudieren tener los Incoterms en las compraventas internacionales, es así que su validez jurídica proviene directamente de la Convención de Viena que, a través de lo dispuesto en el art. 9.2, los eleva a rango de ley dentro de un Estado que la ha incorporado en su ordenamiento jurídico (Ruiz Castellanos, 2012).

En la opinión de Rodríguez Fernández (2010) la elección voluntaria para incorporar los términos encuentra su sustento en el art. 6 del citado instrumento siendo que establece la posibilidad que las partes desplacen total o parcialmente las normas de la Convención en favor de normas o regulaciones ajenas al mismo, que en este caso podrían ser los Incoterms; es oportuno considerar que tanto el art. 6 y 9 son complementarios, siendo fieles al fin primordial del comercio como es la celeridad y adaptabilidad del mismo a las nuevas prácticas comerciales, por ende la Convención va más allá de un simple texto normativo, lo cual permite la

\section{DERECHO GLOBAL. ESTUDIOS SOBRE DERECHO Y JUSTICIA}


integración de la Lex Mercatoria. Es necesario que vendedores y compradores estén debidamente informados de los usos y las costumbres, por tal razón la invocación a estos términos debe ser expresa en las cláusulas del instrumento contractual (Acosta, Felipe, 2002).

Un ejemplo palpable de esto viene dado por la Comisión de las Naciones Unidas para el Derecho Mercantil Internacional (CNUDMI, 2010) donde un tribunal arbitral se ha ocupado de la relación entre el párrafo 2 del artículo $9 \mathrm{y}$ los Incoterms, tras afirmar que están incorporados en la Convención en virtud el párrafo 2 del artículo 9; el tribunal indicó que, con arreglo al párrafo 2 del artículo 9, las definiciones de los Incoterms deben aplicarse al contrato aunque no haya una referencia expresa a ellos en éste. Así, el tribunal sostuvo que, al incorporar un término CIF a su contrato, las partes tenían la intención de aludir a la definición de ese término contenida en los Incoterms.

Todo parece ser que, mientras los Incoterms encuentren asidero o sustento legal en la Convención de Viena, su invocación o aplicación estará ajustada a un marco normativo que puede hacerse valer en los Estados partes; sin embargo habría que interrogarse ¿Qué sucedería si los Incoterms se invocaran como Derecho del contrato sin el sustento de la Convención?, en un primer momento se cuenta con la postura de Ruiz Castellanos (2012) quien exterioriza que fuera del ámbito de aplicación de la Convención de Viena, los usos y costumbres aplicados al contrato deberán erigirse únicamente como Lex Mercatoria lo cual quedaría a merced de las del reconocimiento o no de los Estados, aunque bien, se analizó que hoy en día este nuevo sistema encuentra su fundamento en la autonomía conflictual de las partes en las contrataciones internacionales; no obstante, es menester examinar si los Incoterms pueden aplicarse como Lex Mercatoria.

\section{Aplicación de los Incoterms como Lex Mercatoria (usos y costumbres) a partir de la Autonomía conflictual}

Continuando con el objetivo de esta investigación, se trae colación el aporte de Ortega Giménez, quien expresa que los Incoterms son un reflejo de la 
Eduardo Andrés Calderón Marenco

denominada Lex Mercatoria -o Derecho de los comerciantes- esto es, un Derecho creado por los comerciantes con el fin de simplificar los intercambios comerciales internacionales, que regulan las condiciones más comunes usadas en el comercio internacional y tienen como objetivo establecer criterios definidos sobre la distribución de los gastos y la transmisión de los riesgos entre dos partes, compradora y vendedora, en un contrato de compraventa internacional (Ortega Giménez, 2008).

Bajo el concepto de Lex Mercatoria tal como se enuncio en precedencia, pueden ser acogidos dentro del mismo, dado que se han reconocido como son usos y costumbres compilados desde 1936 por la Cámara de Comercio Internacional, procurando facilitar una serie de términos de forma universal, en los contratos de compraventa internacional de mercaderías, especificando los derechos y obligaciones de las partes bajo cada uno de ellos. Igualmente, el carácter de los usos y costumbres es característico de los Incoterms el cual deviene de su naturaleza jurídica, pero más significante resulta su generalizada utilización y la gran difusión con la que cuentan hoy en día. Oviedo Albán (2003) y Osvaldo Marzorati (1993) refuerzan esta tesis considerando que los Incoterms no se imponen a los contratantes si no es por medio de los acuerdos de voluntades, tal cual como se realiza con los usos y costumbres aplicables internacionalmente y destinados a facilitar la interpretación de los términos comerciales comúnmente utilizables.

La doctrina mayoritaria enmarca a los Incoterms como usos y costumbres internacionales, sin embargo existen posiciones contradictorias, entre ellas la de Boyeras Schumann (2012) debido a que considera que los usos se caracterizan por su espontaneidad, cuestión evidente en su elaboración, además se trata de una práctica social espontánea, distintivo que para él no poseen los Incoterms, a pesar de la labor formuladora de la Cámara de Comercio Internacional (CCI), porque no se limita, a constatar o fijar por escrito unos ya existentes, es decir que su labor fue una recopilación comparativa de diversas cláusulas de estilo que existían en ese entonces y que se han ido modificando con el tiempo, pero que además pueden ser modificables por las partes; mientras que los usos constituyen normas irreflexivas, en el sentido de que su gestación se produce de forma espontánea, los Incoterms se elaboran conforme a un plan preconcebido y en atención a unas finalidades muy concretas. 
En lo particular, no se comparte la opinión de Boyeras Schumann (2013) debido a que estos instrumentos configuran la cristalización de una serie de prácticas comerciales internacionales, que se han normalizado e incorporado a los distintos sistemas estatales, que se emplean para armonizar las operaciones internacionales de comercio internacional, además, lo singular de la Lex Mercatoria es su generalizada utilización y gran difusión, mismo con lo que ya cuentan los Incoterms, máxime que los cambios que se han realizado son resultados de nuevas costumbres instituidas por el resultado de su utilización, y que gracias a su calidad técnica permiten acompañar la práctica mercantil con el desarrollo económico y tecnológico (Ruiz Castellanos, 2016).

Es así, que al hablar de Incoterms es viable parlamentar de una nueva Lex Mercatoria configurada como un nuevo ordenamiento jurídico en el tráfico comercial internacional utilizado por las partes; es por tanto que podemos afirmar que cuando los Incoterms no encuentren su sustento legal devenido de la invocación de la Convención de Viena de 1980, podrán ser incorporados al contrato como Derecho aplicable mediante la autonomía de la voluntad en calidad del ordenamiento jurídico creado por la Lex Mercatoria. Para sostener esta afirmación, Oviedo Albán (2011) indica que las partes en uso de la libertad de pacto (autonomía conflictual), pueden escoger el Derecho a aplicar tomando en cuenta a la Lex Mercatoria, más aun que cada vez con mayor frecuencia se encuentran ordenamientos que permiten en sus leyes de arbitraje, que las partes pacten como aplicable un derecho no estatal.

A pesar de todas estas acertadas reflexiones analíticas en base a la experiencia de la doctrina, los Incoterms como Lex Mercatoria pueden tener algunas complicación al momento de aplicación en base a la autonomía de la voluntad, si bien es cierto, al culmen de este análisis, se forjó y demostró que no solo las leyes estatales pueden ser invocadas por las partes en las contrataciones internacionales, sino que también el nuevo ordenamiento jurídico que se encuentra en boga de la sociedad de comerciantes a nivel internacional. 
Eduardo Andrés Calderón Marenco

\section{Aportes y Resultados}

El presente estudio toma como punto de partida el análisis de los negocios jurídicos de contratación internacional, en concreto la compraventa internacional de mercaderías entre particulares de domicilios de diferentes Estados, en tanto, en estas transacciones se ven envueltas un sin número de derechos y obligaciones. Especialmente, esta investigación resaltó de manera categórica la facultad que tienen los particulares de elegir el Derecho aplicable a su contrato. Tradicionalmente, las partes en virtud del Derecho Internacional Privado han invocado legislaciones estatales para la regulación de sus contrataciones o, en su defecto, la elección de la norma aplicable al arbitrio del tan conocido método conflictual.

Modernamente, resalta la denominada autonomía conflictual en contraste con el método tradicional conflictualista, y es que, en relación a este último sistema se fundamenta sobremanera la falta de adecuación a las necesidades del comercio internacional, por lo tanto, la práctica internacional ha confirmado que las leyes locales no regulan las necesidades del comercio en el ámbito internacional. La elección de un Derecho nacional no ofrece una seguridad total, siendo que el ordenamiento jurídico de un Estado puede presentar lagunas o no estar adaptado a las necesidades de estos negocios jurídicos; por lo que se puede afirmar de manera categórica que este método (norma de conflicto) ha resultado complicado, debido al hecho, como bien se mencionó en el cuerpo de la investigación, de que las normas de conflicto tienden a "nacionalizar" la problemática, lo que es disonante en el ámbito del comercio internacional.

El principio de libertad de elección de un Derecho se configura como una salida para el dilema que genera el método conflictual tradicionalista, que ha imperado conforme del pasar del tiempo. Este principio reconocido por la doctrina y la práctica se conoce como autonomía conflictual, la cual se desprende de la autonomía de la voluntad de las partes y se ha consagrado como garantía de seguridad jurídica en las transacciones comerciales. Las contrataciones internacionales presentan particularidades con relación a este tema (Derecho aplicable), de modo que las partes tiene derecho a elegir en su negocio jurídico

\section{8}


normas de un Derecho sustantivo nacional e internacional, o bien una ley uniforme o de todos aquellos instrumentos internacionales que hayan sido incorporados al Derecho nacional (convenciones, tratados, etc.), pero además, este Derecho puede ubicarse como parte de lo que se denomina Lex Mercatoria (usos y costumbres).

Esta nueva Lex Mercatoria se erige, según la doctrina más aceptada, como usos y costumbres de mayor incidencia en el tráfico internacional, recogiendo y evidenciando las prácticas más usuales que los comerciantes utilizan en sus contratos internacionales, además como un cuerpo "anacional" de reglas, por lo cual su contenido y aplicación es igual, así como al de cualquier cuerpo normativo internacional. Es evidente que es un nuevo ordenamiento jurídico aplicado por los comerciantes y, en la actualidad, por los tribunales arbitrales, y en algunos casos los tribunales nacionales han concedido valor a este nuevo Derecho que se configura a partir de la autonomía de la voluntad de las partes (autonomía conflictual).

En este mismo sentido se estableció el contenido de la Lex Mercatoria, y es que los usos constituyen un derecho espontáneo, uniforme, y en cierta medida universal. De forma adicional, se afirma de manera categórica que, además de los usos, los contratos internacionales y los laudos arbitrales son fuente de los de este nuevo Derecho. En suma, puede decirse que el reconocimiento y la valoración de la nueva Lex Mercatoria en el contexto actual del comercio internacional sustenta la existencia y aplicación de un cuerpo normativo que, en sí, reúne usos de comercio respetados universalmente y que, como tal, dan cabida a la creación de normas jurídicas de imperativo cumplimiento, y su reconocimiento o aprobación viene dado por la autonomía conflictual.

Una manifestación de la Lex Mercatoria son los Incoterms, que desde 1936 se han incorporado en la práctica de los comerciantes en los contratos de compraventa internacional. Es oportuno establecer que son verdaderamente usos y costumbres que han evolucionado y se han adaptado a los cambios que precisa el comercio por su rapidez. Por tanto, se asevera de manera concluyente que los Incoterms forman parte de la Lex Mercatoria, de tal manera que pueden ser invocados por las partes como Derecho aplicable.

La Convención de Viena de 1980 sobre compraventa internacional de mercaderías brinda el sustento legal a estos términos comerciales, y es que en 
Eduardo Andrés Calderón Marenco

el artículo 6 de la citada convención se establece la posibilidad de que las partes desplacen total o parcialmente las normas de la Convención en favor de normas o regulaciones ajenas a la misma, que en este caso podrían ser los Incoterms. Así mismo, el artículo 9 de este cuerpo normativo permite la incorporación de usos y costumbres en el contrato de compraventa internacional de mercaderías, por tanto para los Estados partes no existiría ningún problema en el reconocimiento de los Incoterms; no así para aquellos Estados que no la han ratificado, de modo que las partes deberán aplicar estos términos como Derecho mediante la autonomía conflictual.

Es entonces que, esta investigación demostró, ampliamente, que los Incoterms son usos y costumbres, característica que deviene de su generalizada utilización y la gran difusión con la que cuentan hoy, por tanto están amparados por el nuevo ordenamiento jurídico que se denomina Lex Mercatoria. Tomando en consideración esta posición, las partes pueden invocarlos por la autonomía conflictual como Derecho aplicable en la compraventa internacional de mercaderías. Sin embargo, esta consideración no está totalmente exenta de problemas, debido a que ellos pueden presentar limitantes en su aplicación, dado que la autonomía conflictual está limitada por los Derechos estatales, y sus normas de orden público coartan la autonomía de la voluntad privada, además, la problemática se agudiza en los Estados que no pertenecen a la Convención de Viena de 1980, o bien, en los contratos que no la han aplicado como Derecho, por lo que los Incoterms tendrán que enfrentar estas limitantes derivadas de Derecho local.

\section{Bibliografía}

Acosta, F. (2002). Incoterms, Términos de Compraventa Internacional. México: Ediciones Fiscales ISEF.

AFI (2019). Los Incoterms se renovarán en 2020. Informe, (709). Recuperado de http://azure.afi.es/ContentWeb/EmpresasUnicaja/ incoterms/se/renovaran/en/2020/contenido_sidN_1052249_ sid2N_1052384_cidlL_1824695_ctylL_139_spN_0_climN_5 scidN_1824695_utN_3.aspx?axisU=informe.pdf

\footnotetext{
110 DERECHO GLOBAL. ESTUDIOS SOBRE DERECHO Y JUSTICIA
} 
Alzate Ossa, M. (2013). "Los Incoterms, el contrato de seguro y la compraventa internacional de mercaderías: la transferencia del dominio y del riesgo en el contrato de compraventa internacional y los Incoterms, y su relación con el interés asegurable y la cobertura en el contrato". PRINCIPIA IURIS, (19), 269-324.

Arellano García, C. (2006). Derecho Internacional Privado. Argentina: Porrúa.

Bouza Vidal, N. (2005). "Aspectos actuales de la autonomía de la voluntad en la elección de la jurisdicción y ley aplicables a los contratos internacionales". Recuperado de: http:/www.ehu.eus/ cursosderechointernacionalvitoria/ponencias/pdf/2004/2004_5.pdf

Boyeras Schumann, D. (2012). La compraventa internacional de mercaderías la modalidad FOB (Tesis Inédita de doctorado). Universidad Autónoma de Barcelona, España.

Calderón Marenco, E. A. (2017). “Aplicación normativa de la compraventa internacional de mercaderías", Revista de Derecho, (22), 37-60.

Cámara de Comercio Internacional (2010). Reglas de ICC para el uso de términos comerciales nacionales e internacionales. Barcelona: Apograf S.A.

Chuliá Vicent, E., \& Beltrán Alandete, T. (1995). Aspectos jurídicos de los contratos atípicos. Barcelona: José María Bosch Editor.

Comisión de las Naciones Unidas para el Derecho Mercantil Internacional (2010). Compendio de jurisprudencia basada en la Convención de las Naciones Unidas sobre los Contratos de Compraventa Internacional de Mercaderías. Nueva York: Naciones Unidas.

Dávalos Fernández, R. (2003). "La regulación jurídica del contrato internacional", Revista Cubana de Derecho, (21), 4-56.

Espinoza Quintero, L. (2009). "Principio de Autonomía de la Voluntad e instrumentos de carácter internacional en el sistema jurídico colombiano", Civilizar ciencias sociales y humanas, 9 (16), 15-40.

Espugles Mota, C., \& Iglesias Buhiges, J. L. (2009). Derecho Internacional Privado. Valencia: Tirant lo Blanch. 
Fernández Rozas, J. C., Arenas García, R. \& De Miguel Asensio, P. A. (2013). Derecho de los negocios internacionales (4ta ed.). Madrid: Iustel.

Fernández Rozas, J. C. (2004). Anuario de Derecho Internacional Privado. Madrid: Iprolex.

Fratalocchi, A. (1994). Incoterms contratos y comercio exterior. Buenos Aires: Ediciones Macchi.

García Castillo, T. (2010). La lex contractus en los contratos internacionales. En R. Méndez Silva (Ed.), Contratación y arbitraje internacionales (pp. 63-89). México: UNAM. .

Giménez Corte, C. (2002). LexMercatoria, garantías independientes y coacción extra estatal. Revista de Derecho Internacional y Mercosur, (3), 343-361.

Gómez Segade, J. A., \& García Vidal, A. (2010). El Derecho Mercantil en el Umbral del Siglo XXI. Madrid: Marcial Pons.

González Martín, N., \& Rodríguez Jiménez, S. (2010). Derecho Internacional Privado. México: Nostra Ediciones.

Huamán Sialer, M. A. (2013). Comentarios a las innovaciones de los Incoterms 2010. LEX, 12, 321-346.

Jerez Riesco, J. L. (2007). Comercio Internacional (3 ed.). Madrid: ESIC Editorial.

Leible, S. (2011). La importancia de la autonomía conflictual para el futuro del derecho de los contratos internacionales. Cuaderno de Derecho Transnacional, 3 (1), 214-233.

León Robayo, E. I. (2019). La nueva lex Mercatoria en el derecho latinoamericano de contratos. Bogotá: Tirant lo blanch.

Marzorati, O. (1993). Derecho de los Negocios Internacionales. Buenos Aires: Astrea.

Navarro Pentón, A. G. (2009). Régimen jurídico de la compraventa internacional de mercaderías en Europa y América latina:¿Un sistema suficiente? (Tesis Ineditita de Doctorado). Universidad de Granada, España. 
Ortega Giménez, A. (2008). Contrato de compraventa internacional de mercaderías. Confianza en el Comercio. Madrid: ICEX.

Ortiz Vidal, M. D. (2012). Contratación Internacional y espacio jurídico europeo: el principio de proximidad en el Reglamento de Roma I (Tesis Inédita de doctorado). Universidad de Zaragoza, España.

Oviedo Albán, J. (2003). "Instituciones jurídicas en procesos de integración y globalización: la formación del contrato de compraventa internacional de mercaderías", Vniversitas, (105), 463-552.

Oviedo Albán, J. (2011). Estudios sobre la compraventa internacional de mercaderías. Aplicaciones jurisprudenciales. Saarbrucken: Editorial Academia Española.

Oviedo Albán, J. (2012). Autonomía conflictual en los contratos de compraventa internacional de mercaderías. Colombia: Editorial Ibañez.

Oviedo Albán, J. (2012). La ley aplicable a los contratos internacionales, Revista colombiana de Derecho Internacional, (21), 117-157.

Pereznieto Castro, L. (1999). Derecho Internacional Privado (7ma ed.).

México: Oxford.

Pereznieto Castro, L.; Silva Silva, J. A. (1995). Derecho Internacional Privado. Parte Especial. México: Oxford.

Requejo Isidro, M. (2013). "Elección de la ley aplicable y responsabilidad extracontractual: ¿Cambio de orientación en el modelo conflictual?” Revista de Derecho, (8), 205-234.

Revoredo de Mur, D. (1994). "La autonomía de la voluntad y la ley aplicable al contrato internacional", Themis, (30), 231-241.

Rodríguez Fernández, M. (2010). “Los Nuevos Términos Comerciales Internacionales -INCOTERMS- (Versión 2010) y su aplicación en el Derecho Colombiano". Revista e-Mercatoria, 9 (2), 1-73.

Rodríguez Fernández, M. (2012). "Reconocimiento de la Lex Mercatoria como normativa propia y apropiada para el comercio internacional", Revista e-Mercatoria, II (2), 45-84. 
Ruiz Castellanos, E. (2012). "El valor de los Incoterms para precisar el juez del lugar de entrega", Cuadernos de derecho transnacional, 4(2), 93-122.

Ruiz Castellanos, G. (2016). "La nueva Lex Mercatoria", Revista Boliviana de Derecho, (21), 340-351.

Ruiz Rodríguez, V. (2009). Filosofía del Derecho. Toluca, México: Instituto Electoral del Estado de México.

Sosa C., R. (2012). Uso y utilidad de los Incoterms 2010 en el comercio, aduanas y contratos de compraventa internacional. Ciudad de México: Carpenter Consulting Group.

Tobar Torres, J. A. (2012). "La nueva Lex Mercatoria o de cuando la realidad supera la ficción. Ataques y defensas de la nueva Lex Mercatoria en el comercio internacional", Pensamiento Jurídico, (34), 239-274.

Cómo citar el artículo: Calderón, E. A. (2020). Los Incoterms a través de la Autonomía Conflictual. Derecho Global. Estudios sobre Derecho y Justicia, 5 (13), pp. 87-114. https://DOI.org/10.32870/dgedj.v0i13.245 